\title{
Schizophrenia and violence: from correlations to preventive strategies ${ }^{\dagger}$
}

\author{
Paul E. Mullen
}

Abstract People with schizophrenia make a significant contribution to violence in our communities and, in so doing, often lay waste to their own lives. The $10 \%$ or so from which will emerge the perpetrators of most of the serious violence are identifiable in advance. A structured programme in which the criminogenic personality and behavioural factors, substance misuse and social dislocation are managed together with the active symptoms of the disorder could prevent the progress to violence. Such systems of care could significantly reduce serious criminal violence and homicide, reduce the number of people with schizophrenia who end up in prison, stop the rising number of forensic psychiatric beds and, most importantly, improve the lives of many of the most disturbed and disadvantaged of those with the disorder.

My aim in this article is to move the debate about schizophrenia and violence forward to consider the evidence on what mediates that association and, more importantly, what could be done to reduce the violence. I will begin by presenting evidence in support of a substantial and clinically relevant association. Next, I will review the research on factors that mediate between having a schizophrenic syndrome and behaving in an antisocial manner. Finally, I will suggest ways in which current clinical practice could be modified, and augmented, to break the links between having schizophrenia and behaving violently.

\section{The correlations}

There is a correlation between having a schizophrenic syndrome and increased rates of antisocial behaviour in general and violence in particular (Hodgins, 1992; Hodgins et al, 1996; Wallace et al, 1998; Angermeyer, 2000; Arsenault et al, 2000; Walsh et al, 2001). The evidence that such associations are not just statistically but clinically and socially significant is now overwhelming (Hodgins \& Müller-Isberner, 2004). Why, if the connection is so clear, has it not been widely recognised by clinicians and service planners? Equally puzzling, why have so many researchers and

${ }^{+}$This article is an edited version of the Plenary Lecture delivered at the Royal College of Psychiatrists' Annual Meeting held in Edinburgh, 2005. reviewers in the field (myself on occasion included) either obfuscated or minimised the importance of the correlations to the point of irrelevance?

Studies suggest that in prisons throughout the Western world $5-10 \%$ of those awaiting trial for murder will have a schizophrenic disorder (Table 1). The true figure for the rates of schizophrenia among homicide offenders is likely to be at the higher end of these estimates, as nearly all the studies have systematic biases that underestimate the level of the association. The study of Taylor \& Gunn $(1984 a, b)$, which remains one of the most methodologically robust, concluded that $11 \%$ of homicide offenders and $9 \%$ found guilty of non-fatal violence had schizophrenia. Follow-up studies of large numbers of people with schizophrenia confirm the high levels of violent offending (Soyka et al, 2004; Wallace et al, 2004; Vevera et al, 2005; Swanson et al, 2006).

Conversely, clinicians may never see a patient who has committed a homicide or serious act of interpersonal violence. Up to $10 \%$ of homicide offenders may have schizophrenia, but the annual risk that a person with schizophrenia will commit a homicide is in the region of 1 in 10000 and that of acquiring conviction for violence is 1 in 150 (Wallace et al, 2004). The apparent paradox is because serious violence, and homicide in particular, is far rarer in our community than most realise. The annual homicide rate in the UK is about 1 in 100000 , so even a tenfold increase in risk among those with schizophrenia will not necessarily affect the individual clinician, although it most certainly will affect the community as a whole.

Paul E. Mullen is Professor of Forensic Psychiatry at Monash University, Melbourne, and Director of Forensic Mental Health Services for the State of Victoria (Victoria Institute of Forensic Mental Health, Thomas Embling Hospital, Locked Bag 10, Fairfield, Victoria 3078, Australia; email: paul.mullen@forensicare.vic.gov.au). His research interests are stalking, the relationship between mental disorder and offending behaviour and the long-term effects of child abuse. 
Table 1 Studies from a range of countries showing the probability that homicide offenders have schizophrenia

\begin{tabular}{llccrr}
\hline Study & Country & Homicides, & $\begin{array}{c}\text { Offenders } \\
\text { with schizophrenia, } \%\end{array}$ & OR $^{1}$ & $(95 \%$ CI) \\
Hafner \& Boker (1982) & (West) Germany & 367 & 8.0 & 12.7 & $(11.2-14.3)$ \\
Eronen et al (1996) & Finland & 1037 & 6.1 & 9.7 & $(7.4-12.6)$ \\
Wallace et al (1998) & Australia & 168 & 7.2 & 10.1 & $(5.5-18.6)$ \\
Erb et al (2001) & Germany & $290^{2}$ & 10.0 & 16.1 & $(11.2-12.5)$ \\
Schanda et al (2004) & Austria & 1087 & 5.4 & 8.8 & $(6.7-11.5)$ \\
1. Odds ratio that a homicide offender has schizophrenia. & & &
\end{tabular}

Minor forms of assault in schizophrenia are more common (5-15\% per year), but they are often conceptualised by clinicians not as illness-related but as contextual, personality-based or intoxicationdriven. The problems created by the antisocial behaviour are further obscured from clinicians because so many who offend are invisible behind prison walls. Schizophrenia is 10 times more common in prisons than would be expected by chance (Fazel \& Danesh, 2002). Hopefully, the recent reforms in the UK that take community mental health teams into prisons will bring these lost patients once more to the attention of services.

In short, for the clinician day-to-day experience says one thing, epidemiology says something else. Time to listen to our science - or it would be if researchers spoke with a consistent, let alone, single voice.

The minimising or dismissal of the correlations between schizophrenia and violence by researchers and academics is less easily explained. In part it is due to misplaced good intentions. Many of us began our research in the area attempting to demonstrate that the public's fear of the violence of people with mental disorders were ill-founded. This they are, in the sense of being exaggerated but not, as it has turned out, in the sense of being groundless. The move to put the increased violence in proper perspective has all too often slid into dismissive minimisation.

The other problem in evaluating research in this area lies in fundamental methodological confusions. An example is what should be controlled for prior to calculating the correlation between schizophrenia and violence. Confounders create apparent correlations by relating positively, but independently, to both schizophrenia and violent behaviour. Mediators are products or effects of the schizophrenic state that directly or indirectly contribute to violence (Fig. 1). It may be legitimate to control for confounders but controlling for mediators will reduce or obscure significant relationships. Distinguishing in advance between a confounder and a mediator is not easy. This is in part because many of the factors we are interested in, such as substance misuse, socio-economic class and even personality traits, may be both confounders and mediators. In practice, therefore, the sensible approach is to calculate overall correlations and then ask why the correlation exists.

\section{Mediators}

\section{Substance misuse}

There is a substantial body of opinion, particularly in the USA, that the major driver of crime and violence in people both with and without mental disorder is substance misuse. Epidemiological evidence in schizophrenia supports the strength of the correlation between substance misuse and criminal behaviour (Swanson et al, 1990; Steadman et al, 1998; Soyka, 2000; Steele et al, 2003; Wallace et al, 2004). Individuals with schizophrenia who also misuse drugs and alcohol are currently responsible for most offending behaviour, and some studies report that rates of violence among people with schizophrenia but no known substance use problems are no higher than those for control populations (Monahan et al, 2001). The authors of the influential MacArthur study even suggested that schizophrenia in the absence of substance misuse is a protective factor against violent behaviour (Steadman et al, 1998).

Given the prestige of Steadman and his co-authors this assertion has been widely accepted. However, as noted above, controlling for a mediator in effect controls for the influence of the schizophrenia. Furthermore, you can only conclude that substance misuse itself is a causal factor when you have excluded the possibility that both the violence and the substance misuse are mediated, totally or in part, by a common third factor (case 2 or 3 in Fig. 1). The most likely candidates for such a third factor are personality traits and/or social conditions. The conclusion in the McArthur study that those with schizophrenia who did not misuse substances were no more violent than other members of society is contradicted by studies with far larger numbers of non-substance-misuse cases (Vevera et al, 2005). For example, a study of 2861 people with schizophrenia 


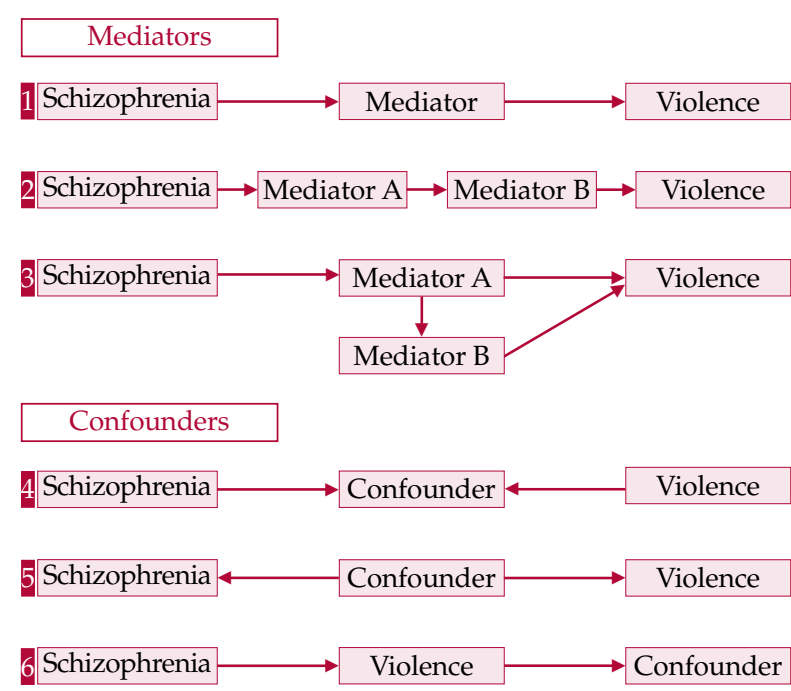

Fig. 1 Mediators have a causal relationship with schizophrenia: they increase the probability of violence (1) and/or they are causally related to a third factor that increases the risk of violence $(2,3)$. Confounders either have a causal but unrelated relationship with both schizophrenia and violence (4) or are the product of both schizophrenia and violence without mediating any connection between the two $(5,6)$. In practice many factors operate partly as mediators and partly as confounders of the relationship.

matched to community controls which covered first admissions over a 25-year period demonstrated that, although over these years the rate of known substance misuse in patients rose from $8 \%$ to $27 \%$, the rate of convictions for violence increased only modestly (from $6 \%$ to $10 \%$ ), in line with the increase among the control group (1\% to 3\%) (Wallace et al, 2004). This paper suggested that those with both schizophrenia and a propensity to violence have moved in increasing numbers into substance misuse over the past 30 years, rather than that those rates of violence have increased in line with the level of substance misuse. This interpretation is supported by the work of two groups: Tengström et al (2004) and Vevera et al (2005). Reducing rates of substance misuse in those with schizophrenia is an important therapeutic goal, central to improving both symptom control and quality of life. Although this will almost certainly decrease antisocial behaviour it is far from a panacea for propensities to violence.

\section{Deinstitutionalisation}

If the popular press and some politicians are to be believed, the root of the problem of criminality among people with serious mental illnesses is deinstitutionalisation and the failure of community care. The only study to examine crime in general among those with schizophrenia over a period of deinstitutionalisation and the introduction of community care found no evidence for an increase in offending relative to offending rates in the general population (Mullen et al, 2000; Wallace et al, 2004). Admittedly, this was in a jurisdiction where adequate funding had been available for the transition, and at the time of the study it remained a comprehensive, reasonably well resourced service. A study of a less well organised and funded process of deinstitutionalisation might have produced different results. However, that would merely demonstrate that bad services, be they community- or asylum-based, produce bad outcomes. For the present there is no scientific basis for attributing any increase in crime to deinstitutionalisation. Those of us old enough to have worked in the large mental hospitals know that their forte was regimenting the institutionalised and harmlessly dysfunctional, not containing the antisocial and violent who then, as now, so often ended up in prison.

\section{Active symptoms}

A substantial body of clinical experience and literature supports a connection between active symptoms and antisocial behaviour, although not all studies support the role of specific phenomena such as delusions and hallucinations (Hafner \& Boker, 1982; Taylor, 1985; Appelbaum et al, 2000; Arsenault et al, 2000). Negative symptoms may even be protective (Swanson et al, 2006). The role of active symptoms in the violence of schizophrenia has, in my opinion, been overestimated, but that they have a role is undoubted. The evidence, for example, of an association between delusional jealousy and attacks on a partner is overwhelming, and persecutory delusions, hallucinations and non-specific psychotic agitation all on occasion precipitate violence (Mullen, 1996; Foley et al, 2005).

There is growing support for a two-type model of violence in schizophrenia (Steinert et al, 1998; Gje et al, 2003). People exhibiting type 1 violence typically have organised delusional systems that are related to the violence, do not have prominent histories of conduct disorder or adult delinquency, usually commit their first violent offence after entering treatment, almost always attack a carer or acquaintance and, perhaps most importantly, 'look like' patients. Those with type 2 violence tend to disorganised clinical syndromes, have histories of conduct disorder, early-onset substance misuse and, usually, violent and non-violent offending prior to diagnosis, commit domestic and non-domestic violence and 'look like' criminals. Most violence 


\section{Box 1 Vulnerabilities that may predispose to violence in schizophrenia}

Vulnerabilities that pre-date the onset of active symptoms:

- developmental difficulties

- dissocial traits

- educational failure

- increased rates of conduct disorder

- non-socialised delinquency

- early-onset substance misuse

Vulnerabilities acquired as a result of active illness:

- active symptoms

- personality deterioration

- social dislocation

- substance misuse

- unemployment

Vulnerabilities imposed:

- drug side-effects, notably akathisia and neuroleptic-induced deficit syndrome

- increased isolation

- erosion of social skills

- incarceration

in the schizophrenia population is attributable to type 2 , although it is possible that among homicide offenders type 1 is overrepresented.

\section{Consequences of the psychopathology of schizophrenia}

A number of the disorders that make up the schizophrenic syndrome manifest from an early age. Schizophrenia can affect the risk of violent behaviour through three types of vulnerability (Box 1):

- vulnerabilities that pre-date the onset of active symptoms

- vulnerabilities acquired as a result of active illness

- vulnerabilities imposed by the results of current treatment and management.

Of the examples listed in Box 1, early-onset substance misuse is of note, as one of the most common clinical errors is to diagnose a drug-induced psychosis in those with schizophrenia whose misuse has preceded their obvious psychotic symptoms.

\section{Developmental factors}

Individuals with schizophrenia who are violent are more likely than both those who are not violent and the general population to have experienced developmental problems and disadvantage during childhood and early adolescence. They come more frequently from deprived and disadvantaged backgrounds, have family histories of criminality, have shown developmental delays, have had educational problems and have had poor peer relationships through childhood and adolescence (Schanda et al, 1992; Tiihonen et al, 1997; Fresan et al, 2004). A history of conduct disorder in childhood, which probably represents in part the concatenation of such factors, is far more common in those with schizophrenia who will be violent and acts as a powerful predictor of such behaviour (Hodgins et $a l, 2005)$. So strong does the relationship appear to be that it works both ways, with those with histories of conduct disorder and juvenile delinquency having an increased risk of developing schizophrenia later in life (Gosden et al, 2005).

\section{Current social context}

People with schizophrenia often fail to develop work and adult social roles even prior to the recognition of their disorder. Once established, schizophrenia is associated with unemployment, which usually brings in its wake financial insecurity and social decline. This tends to encourage a drift into a marginal existence characterised by poor housing, if not homelessness, in socially disorganised neighbourhoods where substance misuse, interpersonal conflict and crime are commonplace. The risk of violence in people with major mental disorders seem to be dramatically increased in those discharged from hospital into high-crime neighbourhoods (Silver, 2000; Logdberg et al, 2004).

\section{Personality factors}

There is now good evidence that personality factors mediate criminality in schizophrenia (Moran et al, 2003; Nolan et al, 1999; Moran \& Hodgins, 2004; Tengström et al, 2004). In part the association has been obscured by the terminology used to describe the vulnerabilities in personality of people with schizophrenia as opposed to offenders. The psychopathic traits of recidivist offenders glory in labels such as lack of remorse, novelty-seeking, impulsivity and callousness. In contrast, the personality damage seen in schizophrenia attracts descriptions such as shallow affect, lack of empathy, lack of realistic long-term goals, irresponsibility, grandiose self-worth and oversensitivity. In fact both groups can be irritable, dissocial, unconcerned about (or blind to) the feelings and interests of others, grandiose, suspicious and negative, can hold unrealistic beliefs of entitlement and fail to 


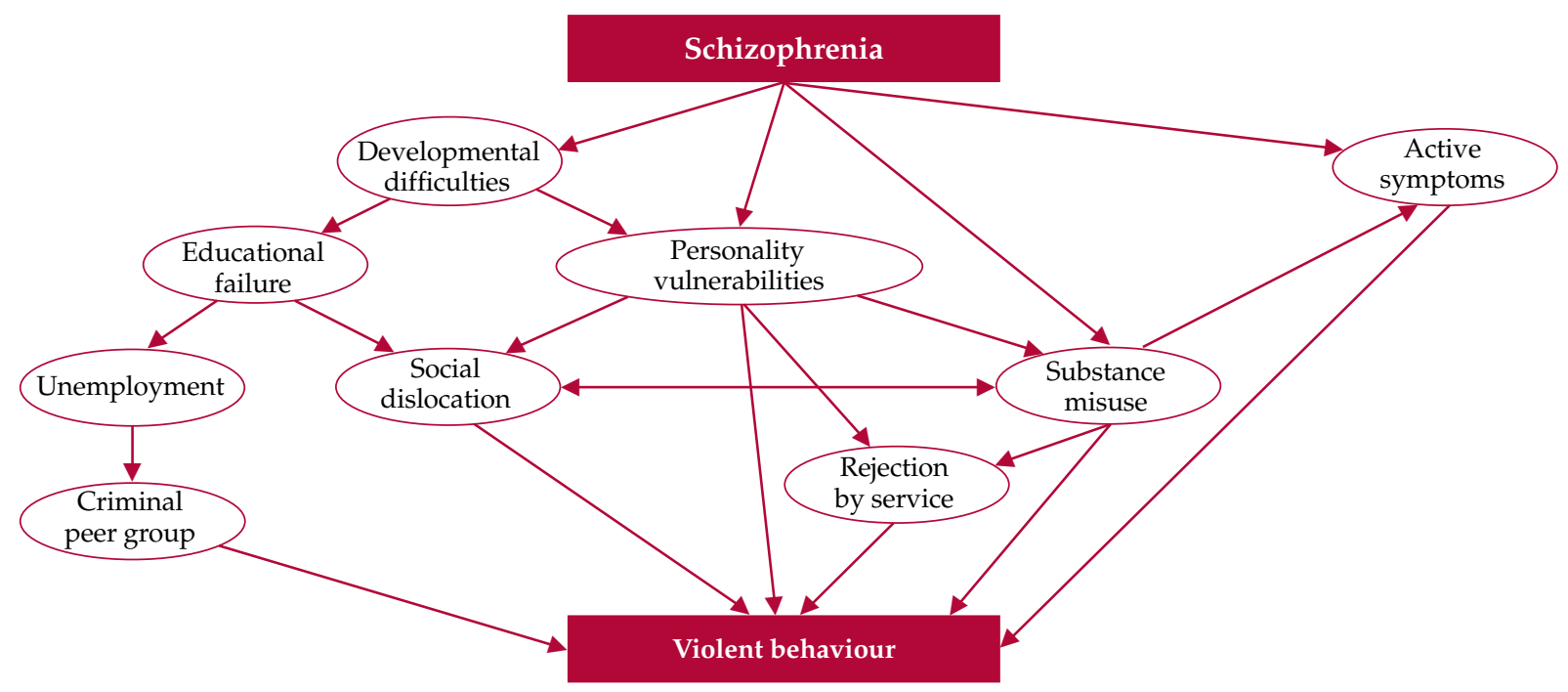

Fig. 2 The major mediators between having schizophrenia and behaving violently. The very complexity of the nexus between illness and violence offers multiple opportunities for intervening to break the links.

learn from experience. Central to the emergence of violence are both the type of person in whom the psychosis manifests and the deleterious effects of the schizophrenic process on their personality.

\section{What is to be done?}

The links that mediate between schizophrenia and violence are represented schematically in Fig. 2. How can we break these links?

It is tempting to lay out some idealised scheme for reducing or removing violence as a complication of schizophrenia. Of course, in an ideal world educational failure would be identified early and remedial steps taken for all children, not just the 0.5$0.8 \%$ who may grow up to develop schizophrenia. Similarly, interpersonal problems, conduct disorder and inadequate parenting would be addressed in childhood to remedy, or at least alleviate, their impact. Identifying pre-psychotic states and intervening early is appealing (McGorry et al, 2005). But it is largely outside of our abilities as clinicians to influence these issues and, until somewhat better evidence for the efficacy of early interventions emerges, probably outside of our ability as scientists to advocate effectively for them. What then are the clinical implications for day-to-day practice?

\section{A changed attitude}

The mental health community has to start by accepting that violent and antisocial behaviours are among the potential complications of having a schizophrenic syndrome. With recognition that the violence is our business comes the possibility of remediation. As long as the problem of violence is minimised or dismissed as 'non-illness related', there can be no progress in reducing risk. Those at high risk of violence, although they constitute less than $10 \%$ of the schizophrenia population, need to be recognised and given an appropriately high priority for management of their illness. But how can they be recognised?

\section{Early identification of high-risk patients}

Identifying those who fall into groups at high risk of future violence should not be an exercise in misplaced stigmatisation but a process of according clinical priority to ameliorating their risk factors. Risk assessment is not some arcane art requiring an expensive induction into a special gnosticism. It is a practical exercise which should be kept simple, clinical, multidisciplinary and systematic.

Simple The high-risk group will include a large number of young males with a history of childhood conduct disorder, antisocial and violent behaviour in adolescence, substance misuse, unemployment and a disorganised lifestyle.

Clinical Risk is dramatically increased in those who are angry and suspicious, lacking insight and rejecting of therapy, threatening and feckless. Specific delusional syndromes, in particular delusional jealousy, dramatically increase risks, as do such personality traits as callousness and belief of entitlement. 
Multidisciplinary No professional group has a monopoly on the knowledge required to evaluate risk, and each needs to make appropriate input. Current ward behaviour, social context, mental state, personality and intellectual evaluations and, above all, a thorough history all play a role.

Systematic The technologies of risk assessment in psychiatric practice have spawned a multiplicity of instruments of widely varying probity. This is not the place to debate the merits of the different checklists. The best use dynamic as well as static variables, thus allowing recognition of which factors can be targeted for reduction. Their prime function for the clinician is to direct attention to known correlates of violent behaviour. They can define high-risk groups. What they cannot do is tell you with acceptable error rates the chances that any particular high-risk individual will be violent. This makes them good as tools for needs assessment and poor as justifications for punitive controls. Instruments such as the HCR-20 (Webster et al, 1997), which incorporates the Psychopathy Checklist, have a place in structuring the professional's approach to risk assessment while at the same time leaving a place for common sense and clinical knowledge.

\section{General principles of management}

Many high-risk patients will be young, substance misusing, rejecting of treatment and disorganised. Management of their schizophrenia depends on enforcing a long enough period of abstinence from cannabis and other drugs of misuse. There is little point in admissions lasting a matter of days, or even a couple of weeks, for in most such cases the patient will still be under the influence of their drugs of misuse. Equally, admission is unlikely to contribute if the patient can pop out regularly to a local dealer or have visitors bring drugs to them. Management depends on extended admissions (4-8 weeks), which may need initially to be to a locked ward. Few individuals in this group will adhere to medication regimens once discharged, nor are they likely to remain in supervised accommodation of their own accord. Community treatment orders can facilitate adherence and, where possible, depot medication is preferable. Given the need to minimise side-effects, particularly akathisia and disruption of frontal lobe function, which can accompany neuroleptic-induced deficit syndrome, secondgeneration atypicals should be the drugs of first choice (Swanson et al, 2004). Currently this restricts the choice to depot risperidone, at least until other atypical depots become available.

Coercion is unlikely to succeed in the long term. If you are going to try to deprive these young people of their drugs, their alcohol and the only peer group they may ever have known, and force on them medications they neither trust nor believe necessary, then you have to provide them some substantial compensations. In the short term, they will need improved accommodation, regular support from professionals with whom they have positive relationships and inputs they value to provide activities and structure in their lives. In the medium term, programmes to improve social interaction, enhance work-related skills and provide recreational and sporting activities may keep their cooperation. Over the long term, if they do not acquire a structured and satisfying existence, be that around work-related activities, recreation or self-help groups, these individuals will remain at constant risk of relapse into substance misuse, downward social drift and crime.

A minority of high-risk patients will have organised paranoid illnesses. At first glance these individuals seem to present a lesser challenge, or at least a more familiar one, as symptoms are the central mediator of risk. In practice, though, they are at least as suspicious and often covertly nonadherent. Possibly because of their detached sense of superiority they are more difficult to engage and more undermining of professionals. They also require extended in-patient care, the use of depot medications and assertive follow-up, particularly as their delusional preoccupations recede only slowly, if at all. They, like the disorganised group, need help with social skills, interpersonal sensitivity, anger management and, above all, effective social reintegration.

\section{Social and occupational management}

High-risk patients leaving hospital need to be placed in stable accommodation in low-crime neighbourhoods. This simple and obvious recommendation is rendered hopelessly idealistic by the resistance to siting hostels, halfway houses and any accommodation for people with mental illnesses, let alone for 'mentally disordered offenders', in more privileged neighbourhoods. The community cannot afford to continue to push the unwanted into areas where reoffending is virtually predetermined.

Those with schizophrenia and at high risk of violence require, on returning to the community, both structure and active supportive engagement. Reoffending by anyone is reduced by employment, stable relationships and mixing with non-criminal peers. The task of instilling work skills in unmotivated, poorly educated people with schizophrenia who have no previous employment experience is considerable. However, mental health services rose to the challenge of rehabilitating chronically 
institutionalised psychiatric patients during the hospital closures of the 1960s and 1970s. Perhaps it is time to take equally seriously the challenge of the young disabled high-risk patients of today.

\section{Psychological management}

Developmental disruptions, genetic predispositions and the process of schizophrenia itself leave some individuals with personality traits and attitudes that can be termed criminogenic. Reducing the possibility of violence depends to a significant degree on modifying these factors and the behaviours they generate.

A pervasive scepticism persists about the effectiveness of managing severe personality disorders in any circumstances, let alone as part of a schizophrenic syndrome. This is in part because the nostrums of the recent past such as dynamic psychotherapies, therapeutic communities, casework and simplistic behavioural therapies either proved ineffective or required sophisticated statistics combined with special pleading to lay claim to any efficacy. Personality disorders as entities may be untreatable, but many of the elements out of which they are constructed are open to modification and improvement. In highrisk schizophrenia it is often possible to improve interpersonal skills, anger control, effective selfassertion and victim empathy and to reduce the cognitive distortions that support the damaging behaviours (Novaco, 1997; Renwick et al, 1997). You cannot create a benign pro-social robust personality, but you can reduce the chances of future antisocial behaviour (Hollin, 2003; McGuire, 2003).

\section{Substance misuse}

The assessment and management of drug and alcohol misuse among those with schizophrenia has perforce become a major priority. In those at high risk of violence, substance misuse is now almost universal and its effective control is a prerequisite for any other management. This is not the place to review or recommend specific approaches to substance misuse other than to reiterate that in both community and in-patient settings it should have a clinical priority similar to that of controlling active symptoms. In our service at the Thomas Embling Hospital we use multiple approaches to optimise outcomes, taking into consideration the patient's readiness to change and working within a harm minimisation framework (e.g. Stanton \& Shadish, 1997; Sheils \& Rolfe, 2000; Mueser et al, 2003). Substance misuse may not be the primary driver of violence in people with schizophrenia, but until it is reduced or, dare one hope, ceases no other preventive strategy will stand much chance.

\section{Restructuring therapeutic goals and service systems}

Whatever is claimed in theory, mental health services, particularly when under pressure, focus primarily on symptom control. Whether this is ever sufficient is doubtful, but in the high-risk groups it is totally inadequate. Substance misuse, personality vulnerabilities and social context need, if not equal priority with symptom control, at least to be a major part of the management process. In part, this will depend on new resources but equally it demands change in the priorities of psychiatric services and in the expectations of the clinicians. For such therapeutic goals to be fully translated into a sustainable system of care will require restructuring of the service delivery system and re-education of all professional staff.

If managing the criminogenic and substance misuse issues in schizophrenia is to have a chance of success it has to involve not just the introduction of a few special programmes but the total immersion of the patient in the drive for change. Central to such a system is the active involvement of ward and community nursing staff. Primary nurses must be aware of and involved in the programmes of their patients. All ward and community staff who may interact with the patient need to be aware of the current goals and management approaches, so as to reinforce the work being done in individual and group therapy. Therapy sessions must cease to be black boxes. They must become transparent manualised approaches, with the why, the what and the goals known not just by the therapist and the patient, but by all relevant staff on a day-by-day basis. Such an approach involves major shifts of practice and of power. Nursing staff become the core of the therapeutic process; psychologists play a far wider role in assessments and programme development for individual patients; social workers and occupational therapists are placed more centrally, particularly in community management. Such changes are a challenge for psychiatrists, who may be tempted to retreat into a focus on the symptoms and narrowly conceived illness issues. If the system is to work, however, psychiatrists are essential and it is only by making a reality of the biopsychosocial ideology of contemporary psychiatry that such an approach will succeed.

The introduction of such a system into our forensic hospital and community services in the state of Victoria over the past 18 months is being evaluated. Already it is associated with decreased ward violence and dramatically increased nurse retention. It is not, however, in forensic but in general mental health services that such restructuring should pay the greatest dividends for patients and the wider community. 


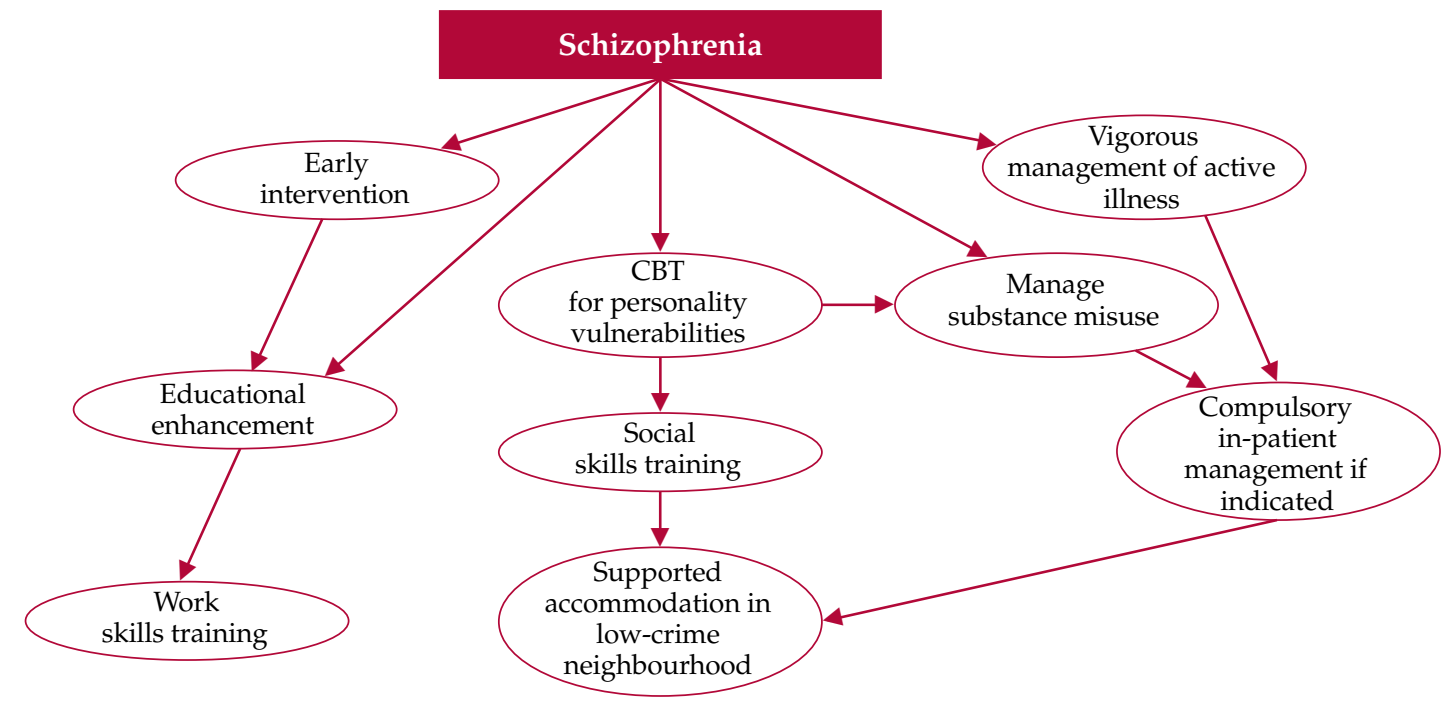

Fig. 3 Interventions that could reduce the strength of the association between having schizophrenia and behaving violently. All interventions depend on accepting that it is the duty of mental health services both to manage the violence that can emerge from schizophrenia and to work with individuals who are misusing substances, delinquent and uncooperative.

\section{Conclusions}

The schizophrenic syndromes are associated with increased rates of violent behaviour. Mental health services have a responsibility to reduce such violence for the sake of their patients as well as the wider community. Most of the violence among those with schizophrenia is perpetrated by members of relatively small subgroups, who probably constitute no more than $10-15 \%$ of the patient population. These high-risk subgroups are recognisable in advance. Importantly, however, only a few even in these groups will ever commit serious acts of violence. This mandates risk management strategies that augment care and treatment for the whole group, rather than justifying policies of coercion and incapacitation directed at selected individuals. Violence by people in the high-risk groups is mediated not just by active symptoms but also by such factors as personality vulnerabilities, social dislocation and coexisting substance misuse.

The prevention of future violence requires approaches that target the criminogenic personality factors, the need for employment and / or structured activities, substance misuse, as well as encouraging appropriate and supportive social networks and relationships. To continue to tolerate a situation where those at highest risk of becoming violent are marginalised or openly rejected by services is problematic. To suggest that simply because a patient is more likely to act violently they should receive better services is equally problematic. However, once we as mental health professionals face up to the fact that reducing violence is part of the legitimate aims of our services the issue becomes a matter of adequate levels of care and treatment for the particular problems, not better or worse services for any particular individual.

\section{Declaration of interest}

None.

\section{References}

Angermeyer, M. C., (2000) Schizophrenia and violence. Acta Psychiatrica Scandinavica Supplementum, 102, 63-67.

Appelbaum, P. S., Robbins, P. C., Monahan, J. (2000) Violence and delusions. Data from the MacArthur Violence Risk Assessment Study. American Journal of Psychiatry, 157, 566-572.

Arseneault, L., Moffitt, T., Caspi, A., et al (2000) Mental disorders and violence in a total birth cohort. Results from the Dunedin Study. Archives of General Psychiatry, 57, 979-986.

Erb, M., Hodgins, S., Freese, R., et al (2001) Homicide and schizophrenia: maybe treatment does a have preventative effect. Criminal Behaviour and Mental Health, 11, 6-26.

Eronen, M., Tiihonen, J. \& Hakola, P. (1996) Schizophrenia and homicidal behaviour. Schizophrenia Bulletin, 22, 83-89.

Fazel, S. \& Danesh J. (2002) Services mental disorder in 23,000 prisoners. A systematic review of 62 surveys. Lancet, 359, 545-550.

Foley, S. R., Kelly, B. D., Clarke, M., et al (2005) Incidence and clinical correlates of aggression and violence at presentation in patients with first episode psychosis. Schizophrenia Research, 72, 161-168.

Fresan, A., Apiquian, R., de la Fuente-Sandoval, C. et al (2004) Premorbid adjustment and violent behaviour in schizophrenic patients. Schizophrenia Research, 69, 143-148.

Gje, X., Brent Donnellan, M. \& Wenk E. (2003) Differences in personality and patterns of recidivism between early starters and other serious male offenders. Journal of the American Academy of Psychiatry and the Law, 31, 68-77. 
Gosden, N..P., Kramp, P., Gabrielsen, G., et al (2005) Violence in young criminals predicts schizophrenia: a 9-year registerbased followup of 15- to 19-year-old criminals, Schizophrenia Bulletin, 31, 759-768.

Hafner, H. \& Boker, W. (1982) Crimes of Violence by Mentally Abnormal Offenders (ed. F. H. Marshall). Cambridge, Cambridge University Press.

Hodgins, S. (1992) Mental disorder, intellectual deficiency, and crime: evidence from a birth cohort. Archives of General Psychiatry, 49, 476-483.

Hodgins, S. \& Müller-Isberner, R. (2004) Preventing crime by people with schizophrenic disorders: the role of psychiatric services. British Journal of Psychiatry, 185, 245-250.

Hodgins, S., Mednick, S., Brennar, P. A., et al (1996) Mental disorder and crime: evidence from a Danish birth cohort. Archives of General Psychiatry, 53, 489-496.

Hodgins, S., Tiihonen J. \& Ross D. (2005) The consequences of conduct disorder for males who develop schizophrenia: associations with criminality, aggressive behavior, substance use, and psychiatric services. Schizophrenia Research, 78, 323-335.

Hollin, C. R (2003) Handbook of Offender Assessment and Treatment. Chichester: John Wiley \& Sons.

Logdberg, G., Nilsson, L.-L., Levander, M. T., et al (2004) Schizophrenia, neighbourhood, and crime. Acta Psychiatrica Scandinavica, 110, 92-97.

McGorry, P., Nordentoff, M. \& Simonsen, E. (2005) Introduction to 'Early psychosis: a bridge to the future'. British Journal of Psychiatry, 187 (suppl. 48), s1-s3.

McGuire, J. (2003) Offender Rehabilitation and Treatment: Effective Programs and Policies to Reduce Re-offending. Chichester: John Wiley \& Sons.

Monahan, J., Steadman, H. J., Silver E., et al (2001) Rethinking Risk Assessment. New York: Oxford University Press.

Moran, P. \& Hodgins, S. (2004) The correlates of comorbid antisocial personality disorder in schizophrenia. Schizophrenia Bulletin, 30, 791-802.

Moran, P., Walsh, E., Tyrer, P., et al (2003) Impact of comorbid personality disorder on violence in psychosis. Report from the UK700 trial. British Journal of Psychiatry, 182, 129-134.

Mueser, K. T., Noordsy, D. L., Drake, R. E., et al (2003) Integrated Treatment for Dual Disorders. A Guide to Effective Practice. New York: Guilford Press.

Mullen, P. E. (1996) Jealousy and the emergence of violent and intimidating behaviours. Criminal Behaviour and Mental Health, 6, 199-205.

Mullen, P. E., Burgess, P., Wallace, C., et al (2000) Community care and criminal offending in schizophrenia. Lancet, 355 614-617.

Nolan, K. A., Volavka, J., Mohr ,P., et al (1999) Psychopathy and violent behaviour among patients with schizophrenia or schizoaffective disorder. Psychiatric Services, 50, 787-792.

Novaco, R. W (1997) Remediating anger and aggression with violent offenders. Legal and Criminal Psychology, 2, 103-116.

Renwick, S. J, Black, L., Ramm, M., et al (1997) Anger treatment with forensic hospital patients. Legal and Criminal Psychology, 2, 103-116.

Schanda, H., Foldes, P., Topitz, A., et al (1992) Premorbid adjustment of schizophrenic criminal offenders. Acta Psychiatrica Scandinavica, 86, 121-126.

Schanda, H., Knecht, G., Schreinzer, D., et al (2004) Homicide and major mental disorders: a 25 year study. Acta Psychiatrica Scandinavica, 110, 98-107.

Sheils, R. \& Rolfe, T. J (2000) Toward an integrated approach to family intervention for co-occurring substance abuse and schizophrenia. Australian and New Zealand Journal of Family Therapy, 21, 81-87.

Silver, E. (2000) Extending social disorganisation theory: a multilevel approach to the study of violence among persons with mental illness. Criminology, 38, 1043-1074.

Soyka, M. (2000) Substance misuse, psychiatric disorder and violent and disturbed behaviour. British Journal of Psychiatry, 176, 345-350.

Soyka, M., Morhart-Klute, V. \& Schoech, H. (2004) Delinquency and criminal offences in former schizophrenic inpatients 7-12 years following discharge. European Archives of Psychiatry and Clinical Neuroscience, 254, 289-294.
Stanton, M. D. \& Shadish, W. R (1997) Outcome, attrition, and family-couples treatment for drug abuse. A meta-analysis and review of the controlled, comparative studies. Psychological Bulletin, 122, 170-191.

Steadman, H. J., Mulvey, E. P., Monahan, J., et al (1998) Violence by people discharged from acute psychiatric inpatient facilities and by others in the same neighborhoods. Archives of General Psychiatry, 55, 1-9.

Steele, J., Darjee, R. \& Thomson, L. D. G. (2003) Substance dependence and schizophrenia in patients with violent and criminal propensities. Journal of Forensic Psychiatry and Psychology, 14, 569-584.

Steinert, T., Voellner, A. \& Faust, V. (1998) Violence and schizophrenia: two types of criminal offenders. European Journal of Psychiatry, 12, 153-165.

Swanson, J. W., Holzer, C., Sanju, V. K., et al (1990) Violence and psychiatric disorder in the community. Evidence from the Epidemiologic Catchment Area surveys. Hospital and Community Psychiatry, 41, 761-770.

Swanson, J. W., Swartz, M. S. \& Elbogen, E. B. (2004) Effectiveness of atypical antipsychotic medications in reducing violent behaviour among persons with schizophrenia in communitybased treatment. Schizophrenia Bulletin, 30, 3-20.

Swanson, J. W., Swartz, M. S., Van Dorn, R. A., et al (2006) A national study of violent behaviour in persons with schizophrenia. Archives of General Psychiatry, 63, 490-499.

Taylor, P. J. (1985) Motives for offending among violent and psychotic men. British Journal of Psychiatry, 147, 491-498.

Taylor, P. J. \& Gunn, J. (1984a) Violence and psychosis. I: The risk of violence among psychotic men. BMJ, 288, 1945-1949.

Taylor, P. J. \& Gunn, J. (1984b) Violence and psychosis. II: Effect of psychiatric diagnosis on conviction and sentencing of offenders. BMJ, 289, 9-12.

Tengström, A., Hodgins, S., Grann, M., et al (2004) Schizophrenia and criminal offending: the role of psychopathy and substance misuse. Criminal Justice and Behaviour, 31, 1-25.

Tiihonen, J., Isohanni, M., Rasanen, P., et al (1997) Specific major mental disorders and criminality: a 26-year prospective study of the 1966 Northern Finland birth cohort. American Journal of Psychiatry, 154, 840-845.

Vevera, J., Hubbard, A., Vesely, A., et al (2005) Violent behaviour in schizophrenia. Retrospective study of four independent samples from Prague, 1949 to 2000. British Journal of Psychiatry, 187, 426-430

Wallace, C., Mullen, P. E., Burgess, P., et al (1998) Serious criminal offending and mental disorder. Case linkage study. British Journal of Psychiatry, 172, 477-484.

Wallace, C., Mullen, P. E. \& Burgess, P. (2004) Criminal offending in schizophrenia over a 25 year period marked by deinstitutionalization and increasing prevalence of comorbid substance use disorders. American Journal of Psychiatry, 161, 716-727.

Walsh, E., Buchanan, A. \& Fahy, T. (2001) Violence and schizophrenia: examining the evidence. British Journal of Psychiatry, 180, 490-495

Webster, C. D., Douglas, K. S., Eaves, D., et al (1997) HCR-20: Assessing Risk for Violence (Version 2). Burnaby: Mental Health, Law and Policy Institute, Simon Fraser University.

\section{MCQs}

1 The association between schizophrenia and violent behaviour:

a is statistically, but not clinically or socially, significant

b should be calculated after allowing for the effects of mediating influences

c is primarily the result of active symptoms such as delusions and hallucinations

d may account for up to $10 \%$ of violent crime, including homicide

e should be taken seriously by clinicians for the sake of their patients and the safety of the community. 
2 Substance misuse in schizophrenia:

a makes any attempt to manage the risk of violence more difficult

$\mathrm{b}$ is a marker for increased risk of future violence

c often manifests prior to the first recognition of psychotic symptoms

d mediates most of the risk of violent behaviour

e should be given high priority in any service system that has as one of its objectives managing schizophrenia in people at high risk of behaving violently.

3 Personality vulnerabilities in schizophrenia:

a are primarily the results of the effects of active psychotic illness

b may precede the onset of active psychosis

c can include such traits as suspiciousness, disregard for the feelings of others and fecklessness which predispose to violent behaviour

d need to be assessed and managed in most people who are at high risk

e are fixed.

4 The social context in which those with schizophrenia live:

a has a major influence on the likelihood of antisocial and violent behaviour

b will inevitably deteriorate as the illness becomes chronic

c can be modified to reduce the chances of violence among the high-risk group d will be dependent to a significant extent on the interpersonal, social and work skills that the individual acquires

e has a major influence on whether any existing substance misuse ameliorates, persists or escalates.

5 Violence in those with schizophrenia:

$a$ is the business of mental health services to try and reduce

$\mathrm{b}$ is overemphasised by the press and politicians

c is the responsibility specifically of forensic mental health services, not general and community services

$\mathrm{d}$ can be prevented by effective control of active symptoms

e may be exacerbated by first-generation antipsychotics.

\section{MCQ answers}

$\begin{array}{lllllll}\text { 1 } & & \text { 2 } & & 3 & 4 & 5 \\ \text { a F } & \text { a T } & \text { a F } & \text { a T } & \text { a T } \\ \text { b F } & \text { b T } & \text { b T } & \text { b F } & \text { b T } \\ \text { c F } & \text { c T } & \text { c T } & \text { c T } & \text { c F } \\ \text { d T } & \text { d T } & \text { d T } & \text { d T } & \text { d F } \\ \text { e T } & \text { e T } & \text { e F } & \text { e T } & \text { e T }\end{array}$

